\title{
Publisher Correction: Chloroquine modulates antitumor immune response by resetting tumor- associated macrophages toward M1 phenotype
}

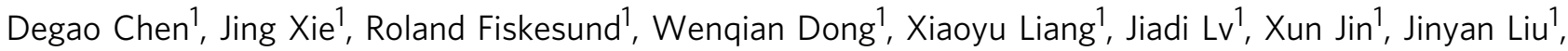
Siqi Mo1, Tianzhen Zhang ${ }^{1}$, Feiran Cheng ${ }^{1}$, Yabo Zhou'1, Huafeng Zhang ${ }^{2}$, Ke Tang ${ }^{2}$, Jingwei Ma ${ }^{2}$, Yuying Liu ${ }^{1,3}$ \& Bo Huang (1) 1,2,3

Correction to: Nature Communications https://doi.org/10.1038/s41467-018-03225-9, published online 28 February 2018.

In the originally published version of this Article, images in Fig. 5n were inadvertently replaced with duplicates of images in Fig. 5o during the production process. This has now been corrected in both the PDF and HTML versions of the Article.

Published online: 01 May 2018

(c) Open Access This article is licensed under a Creative Commons Attribution 4.0 International License, which permits use, sharing, adaptation, distribution and (c) reproduction in any medium or format, as long as you give appropriate credit to the original author(s) and the source, provide a link to the Creative Commons license, and indicate if changes were made. The images or other third party material in this article are included in the article's Creative Commons license, unless indicated otherwise in a credit line to the material. If material is not included in the article's Creative Commons license and your intended use is not permitted by statutory regulation or exceeds the permitted use, you will need to obtain permission directly from the copyright holder. To view a copy of this license, visit http://creativecommons.org/licenses/by/4.0/.

(c) The Author(s) 2018

\footnotetext{
${ }^{1}$ Department of Immunology \& National Key Laboratory of Medical Molecular Biology, Institute of Basic Medical Sciences, Chinese Academy of Medical Sciences, 100005 Beijing, China. ${ }^{2}$ Department of Biochemistry \& Molecular Biology, Tongji Medical College, Huazhong University of Science \& Technology, 430030 Wuhan, China. ${ }^{3}$ Clinical Immunology Center, Chinese Academy of Medical Sciences, 100005 Beijing, China. Correspondence and requests for materials should be addressed to B.H. (email: tjhuangbo@hotmail.com)
} 